\title{
Excretion of benzoic acid derivatives in urine of sheep given intraruminal infusions of 3-phenylpropionic and cyclohexanecarboxylic acids
}

\author{
BY J. H. PAGELLA, X. B. CHEN*, N. A. MACLEOD, \\ E. R. ØRSKOV AND P. J. S. DEWEY \\ Rowett Research Institute, Bucksburn, Aberdeen AB21 9SB
}

(Received 1 July 1996 - Revised 1 October 1996 - Accepted 15 October 1996)

\begin{abstract}
The quantitative relationship between the urinary excretion of benzoic acid (BA) and the uptake of 3-phenylpropionic (PPA) and cyclohexanecarboxylic (CHCA) acids was assessed. PPA and CHCA are produced in the rumen by microbial fermentation of lignocellulosic feeds and metabolized, after absorption, to BA which is excreted in the urine mainly as its glycine conjugate hippuric acid (HA). Four sheep nourished by intragastric infusions of all nutrients were given continuous ruminal infusions of PPA (8, 16 or $24 \mathrm{mmol} / \mathrm{d})$ either alone or with CHCA (8 or $16 \mathrm{mmol} / \mathrm{d})$ in a factorial experiment. The treatments were allocated to ten consecutive $6 \mathrm{~d}$ periods, with a control being repeated at periods 1, 5 and 10. PPA and CHCA ruminal absorption rates, estimated using the liquid-phase marker Cr-EDTA, were 0.78 (SD 0.29)/h and 0.88 (SD 0.28)/h respectively. For the control, HA excretion was only 0.22 (SD 0.33) mmol/d and free BA was absent. For the other treatments, both HA and free BA were present and HA accounted for 0.85 (SD 0.05) of total BA. The urinary excretion of total BA showed a significant linear correlation $(r=0.997, P<0.001)$ with the amounts of PPA and CHCA infused. The urinary recovery of infused PPA and CHCA as total BA was 0.79 (SE 0.01). Faecal excretion of BA and its precursors was negligible. Results of this study show that urinary total BA is a potential estimator of the absorption of PPA + CHCA produced in the rumen.
\end{abstract}

Benzoic acid: Hippuric acid: 3-Phenylpropionic acid: Cyclohexanecarboxylic acid: Sheep

Ruminants excrete large quantities of benzoic acid (BA) derivatives in their urine due to the ingestion of lignocelluosic feedstuffs. The BA derivatives are the excretory products of hydroxycinnamic acids such as p-coumaric, caffeic and ferulic acids (Martin, 1982b) and of hydroxycyclohexanecarboxylic acids such as quinic and shikimic acids (Martin, 1982a). These compounds are involved in the biosynthesis of lignin and are ubiquitous in vascular plants. Since these compounds are of no nutritional value they are often called xenobiotics, that is, foreign to the normal energy-yielding metabolism of the animal (Caldwell, 1989). By reduction and hydrolysis during microbial fermentation in the rumen, the hydroxycinnamic and hydroxycyclohexanecarboxylic acids are converted to phenylpropionic (PPA) and cyclohexanecarboxylic (CHCA) acids respectively. The PPA and CHCA are then absorbed from the rumen and posterior digestive tract compartments, and converted to BA mainly in the liver by oxidative reactions. BA can be excreted in the urine either as the free acid or as its conjugates with glycine or glucuronic acid (Martin, 1978). Fig. 1 shows the metabolic pathways for the formation of BA from PPA and CHCA. Hippuric acid (HA), the glycine conjugate of BA, is quantitatively the most important BA derivative. For

* For reprints. 
ruminants receiving roughage diets (concentration of BA precurors can be as high as $350 \mathrm{mmol} / \mathrm{kg} \mathrm{DM}$ for hydroxycinnamic acids and $100 \mathrm{mmol} / \mathrm{kg} \mathrm{DM}$ for hydroxycyclohexanecarboxylic acids), HA daily excretion can amount to as much as $6 \mathrm{mmol} / \mathrm{kg}$ metabolic body weight $\left(\mathrm{W}^{0.75}\right)$. Endogenous contribution to the urinary total BA is not significant as shown by fasting experiments (Martin, 1973).

Numerous studies on ruminant $\mathbf{N}$ metabolism reported in the literature include measurement of HA, since it is present in the urine in large quantities and is an important urinary carrier of energy and $\mathrm{N}$ for animals receiving roughage diets. Giráldez et al. (1993)<smiles>O=C(O)C1(O)CC(O)C(O)C(O)C1</smiles>

quinic acid<smiles>O=C(O)C1=CC(O)C(O)C(O)C1</smiles>

shikimic acid (<smiles>[V]</smiles>

cyclohexanecarboxylic acid<smiles>O=C(O)c1ccc(O)cc1</smiles>

$p$-coumaric acid<smiles>O=C(O)c1ccc(O)cc1</smiles>

caffeic acid
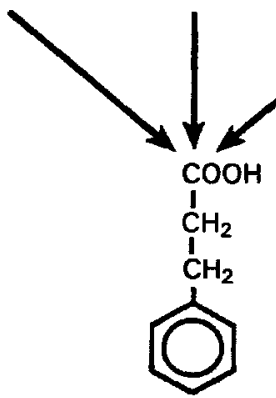

3-phenylpropionic acid

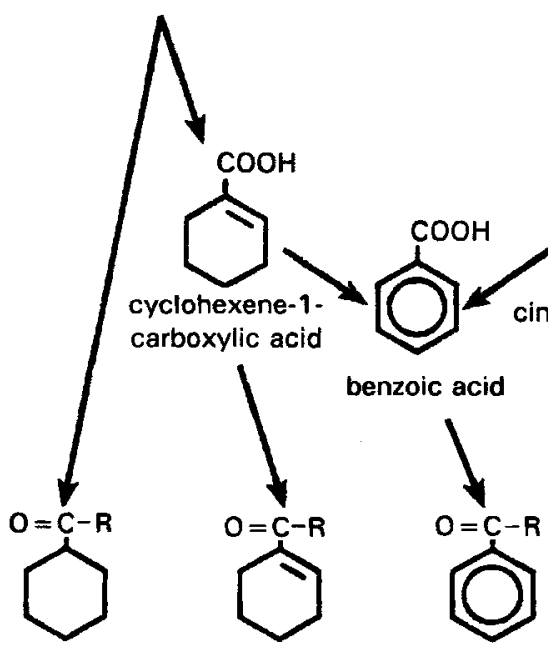<smiles>COc1cc(C=CC(=O)O)ccc1O</smiles>

ferulic acid
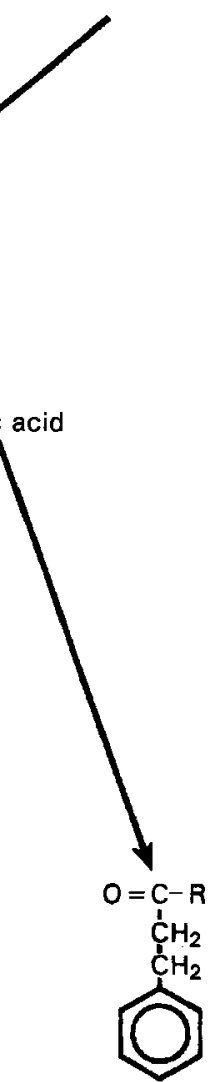

Fig. 1. Schematic illustration of the pathways for the formation of 3-phenylpropionic (PPA) and cyclohexanecarboxylic (CHCA) acids in the rumen as the result of microbial fermentation of cellulosic feed, and for the formation of benzoic acid (BA) from PPA and CHCA after absorption from the rumen. BA is excreted in the urine either free or as its conjugates with glycine or glucuronic acid ( $R$ stands for hydroxyl, glycyl or glucuronyl group respectively). 
used HA excretion to indicate the improvement of roughage digestion after $\mathbf{N}$ supplementation. Results of our previous study indicated that the urinary excretion of BA derivatives is significantly correlated with the intake of cellulosic feed in sheep (Chen et al. 1993). BA excretion could, therefore, provide a measure of the intake of digestible cellulosic feed if the dose-response relationship between the urinary output of BA and absorption of its precurors is known. Studies are in progress in our laboratory to examine the production of PPA and CHCA from their precursors in feeds. The present work is focused on the quantitative relationship between the excretion of BA derivatives and the absorption of the BA precursors PPA and CHCA.

There have been reports of feeding trials in which BA or its precurors were administered to sheep, cattle and goats orally or by intragastric infusion to study the excretion of BA derivatives in the urine (Ringer, 1911; Martin, 1966, 1982a,b; Kreula et al. 1970). However, the quantitative relationship between the absorption of PPA and CHCA and their urinary metabolite BA has not been determined. One common constraint of these dosing experiments is that factors such as contribution from feed BA precurors and rumen microbial activity were not precisely controlled. In the present study, animals nourished by intragastric infusions of all nutrients (Ørskov et al. 1979) were used. The inputs of PPA and CHCA, via ruminal infusion, were precisely controlled.

\section{MATERIALS AND METHODS}

\section{Animals and intragastric nutrition}

Four Suffolk cross wethers (10 months old, initial live weight 53.1 (SD 5.7) kg) fitted with a rumen cannula and an abomasal catheter were used. The animals were initially fed on $900 \mathrm{~g}$ (fresh weight)/d of a hay-concentrate ration $(1: 1, w / w)$. Over a period of $12 \mathrm{~d}$, the solid feed was replaced gradually by intragastric nutrition. All experimental procedures complied with the Animals (Scientific Procedures) Act 1986 of the UK.

A mixture of volatile fatty acids (VFA), buffer and macrominerals was infused into the rumen and a mixture of casein, glucose, vitamins and trace minerals into the abomasum. The VFA mixture contained acetic, propionic and butyric acids in the molar proportion 0.65:0.25:0.10 respectively. Macrominerals and trace minerals were given in fixed amounts, but the other nutrients were given in proportion to metabolic body weight. The energy input consisted of $310 \mathrm{~kJ}$ from VFA, $70 \mathrm{~kJ}$ from glucose and $125 \mathrm{~kJ}$ from casein per $\mathrm{kg} \mathrm{W}^{0.75}$ daily, and was equivalent to 1.2 times the estimated maintenance energy requirement (Agricultural Research Council, 1980). The daily $\mathrm{N}$ input (from casein) was $860 \mathrm{mg} / \mathrm{kg} \mathrm{W}^{0.75}$ and was equivalent to 1.7 times the estimated maintenance $\mathrm{N}$ requirement (Agricultural Research Council, 1980). The procedures for preparation of infusates and infusion routine were as described by MacLeod et al. (1982).

\section{Experimental design and treatments}

There were eight treatments which were combinations of different daily provision of PPA and CHCA. These treatments were (daily infusion level):(1) control (i.e. no PPA or CHCA infused);(2) $8 \mathrm{mmol} \mathrm{PPA;} \mathrm{(3)} 16 \mathrm{mmol} \mathrm{PPA;} \mathrm{(4)} 24 \mathrm{mmol} \mathrm{PPA}$; (5) $8 \mathrm{mmol} \mathrm{PPA}+8 \mathrm{mmol}$ CHCA; (6) $8 \mathrm{mmol}$ PPA + 16 mmol CHCA; (7) $16 \mathrm{mmol} \mathrm{PPA}+8 \mathrm{mmol} \mathrm{CHCA;} \mathrm{and} \mathrm{(8)}$ $16 \mathrm{mmol}$ PPA $+16 \mathrm{mmol}$ CHCA. These levels of infusion were set so that the expected urinary excretions of total BA, if recovery was complete, fell within the range of values reported in the literature (Martin, 1969) for sheep fed with different amounts of roughage. The treatment design was such that the effects of PPA alone or with CHCA on BA 
Table 1. Allocation of treatments used in the experiment*

\begin{tabular}{lcccc}
\hline \hline Period & Sheep 1 & Sheep 2 & Sheep 3 & Sheep 4 \\
\hline 1 & 1 & 1 & 1 & 1 \\
2 & 2 & 3 & 7 & 4 \\
3 & 7 & 5 & 6 & 8 \\
4 & 6 & 4 & 3 & 2 \\
5 & 1 & 1 & 1 & 1 \\
6 & 3 & 8 & 5 & 7 \\
7 & 5 & 2 & 4 & 6 \\
8 & 4 & 7 & 8 & 3 \\
9 & 8 & 6 & 2 & 5 \\
10 & 1 & 1 & 1 & 1 \\
\hline \hline
\end{tabular}

PPA, 3-phenylpropionic acid; CHCA, cyclohexanecarboxylic acid.

* The treatments were (per d): (1) control (i.e. no PPA nor CHCA was infused); (2) 8 mmol PPA; (3) 16 mmol PPA; (4) $24 \mathrm{mmol}$ PPA; (5) $8 \mathrm{mmol}$ PPA $+8 \mathrm{mmol} \mathrm{CHCA}$; (6) $8 \mathrm{mmol}$ PPA + $16 \mathrm{mmol} \mathrm{CHCA}$; (7) $16 \mathrm{mmol}$ PPA $+8 \mathrm{mmol}$ CHCA; and (8) $16 \mathrm{mmol}$ PPA $+16 \mathrm{mmol} \mathrm{CHCA}$.

excretion could be examined by a regression approach. Emphasis was placed on the effect of PPA as this is quantitatively the major precuror of BA (Martin, 1982a). The eight treatments were allocated to the four sheep in ten consecutive periods of $6 \mathrm{~d}$. The control was repeated in periods 1,5 and 10 . In periods $2-4$, and 6-9, an incomplete factorial design was used for the allocation of treatments (see Table 1).

The solutions of PPA and CHCA for infusion were prepared daily and for individual animals separately. The required amounts of PPA and CHCA (both analytical grade, Sigma, Poole, Dorset) were dissolved in 3.5 litres deionized water. $\mathrm{NaOH}$ was added to enhance their solubility. The amount of $\mathrm{NaOH}$ added was $8 \mathrm{mmol}$ in excess of the sum of PPA and CHCA in the infusate (pH of final solution was 9.5-10). The solution was kept homogeneous by continuous stirring with a bench stirrer during infusion. The solutions were infused into the rumen using a peristaltic pump calibrated for complete delivery of the infusate within $23 \mathrm{~h}$.

\section{Sampling of urine and faeces}

Total urine was collected each day into $1 \mathrm{M}-\mathrm{H}_{2} \mathrm{SO}_{4}$ so that the final $\mathrm{pH}$ was about 2 . Samples of urine were stored at $-20^{\circ}$. Faeces were collected daily, bulked for each period for each animal, then oven-dried at $65^{\circ}$ and ground through a $1 \mathrm{~mm}$ sieve with a hammer mill. Faecal samples $(1 \mathrm{~g} D M)$ were mixed in screw-capped glass tubes with $10 \mathrm{ml}$ of a solution containing $150 \mathrm{ml} / \mathrm{l}$ methanol in $20 \mathrm{mM}$-acetic acid (pH 3.3) and shaken by a bench shaker for $4 \mathrm{~h}$. The contents were centrifuged at $15000 \mathrm{~g}$ for $15 \mathrm{~min}$ and the supernatant fractions (referred to as faecal extract) kept at $-20^{\circ}$ until chromatographic analysis.

\section{Measurement of the rates of absorption of phenylpropionic acid and cyclohexanecarboxylic acid from the rumen}

The rates of absorption of PPA and CHCA from the rumen were estimated by comparing the rate of disappearance of the infused compounds with that of the liquid phase marker $\mathrm{Cr}-$ EDTA. The Cr-EDTA solution (54 mmol $\mathrm{Cr} / \mathrm{l}$ ) was prepared according to Binnerts et al. (1968). The measurements were made at the end of period 9. As soon as the infusion of 
PPA or PPA plus CHCA was completed, the infusate was replaced with water and the infusion was continued at the same flow rate. A dose of $50 \mathrm{ml}$ Cr-EDTA solution (containing $2.7 \mathrm{mmol} \mathrm{Cr}$ ) was injected into the rumen via the cannula using a $50 \mathrm{ml}$ syringe attached to a short length of silicone tubing submerged in the rumen fluid. The rumen fluid was mixed also using the syringe. Good mixing was more readily achieved since the rumen of the sheep nourished by intragastric infusions of liquid nutrients was free of solid particles. A sample of rumen fluid was taken immediately after mixing. Further samples were taken at $10 \mathrm{~min}, 1,2,4,8,12,19$ and $24 \mathrm{~h}$ after dosing. The samples were stored at $-20^{\circ}$ until analysis for $\mathrm{Cr}$, PPA and CHCA.

\section{Chemical analysis}

$\mathrm{Cr}$ concentration in rumen fluid was determined by atomic absorption spectrometry (Binnerts et al. 1968). PPA, BA, HA and cinnamic acid (CA), the latter an intermediate in the formation of BA by PPA $\beta$-oxidation, were determined by HPLC (Chen et al. 1996). In the same chromatography, some other aromatic metabolites can also be determined if present, including phenylaceturic acid, phenylacetic acid, and p-cresol. CHCA was determined by a method based on GLC described later.

Glucuronic acid conjugates of BA, phenylacetic and other acids were not commercially available for use as standards. In order to ascertain that the output of all possible forms of BA, PPA, CA or CHCA were taken into account, the urine and faecal extract samples were treated with $6 \mathrm{M}-\mathrm{HCl}$ thereby converting the conjugated metabolites to the free compounds. The procedure was as described by Chen et al. (1996). Untreated rumen fluid, urine samples with and without acid hydrolysis and acid hydrolysate of the faecal extracts were analysed by the HPLC and GLC methods.

The GLC method used for the analysis of CHCA was as follows. Samples of rumen fluid $(3 \mathrm{ml})$, urine $(4 \mathrm{ml})$ or faecal extract $(4 \mathrm{ml})$ were mixed with $200 \mu \mathrm{l}$ of the internal standard, $8.25 \mathrm{mM}$-pentadecanoic acid in methanol, and were extracted with diethyl ether three times using a total of $8 \mathrm{ml}$ diethyl ether. After drying by evaporation using a stream of dry $\mathrm{N}_{2}, 200 \mu \mathrm{l}$ pyridine and $100 \mu \mathrm{l}, \mathrm{N}$-bis(trimethylsilyl)trifluoracetamide (BSTFA), which reacts with carboxylic acids, were added to the samples. The mixtures were heated at $70^{\circ}$ for $15 \mathrm{~min}$ in sealed glass tubes. Derivatized samples were analysed on a Hewlett Packard Model 5890 gas chromatograph (Hewlett Packard, Stockport, Ches.) equipped with an autosampler and a flame-ionization detector. A $30 \mathrm{~m} \times 0.25 \mathrm{~mm}$ i.d. SE-54 coated capillary glass column was used. The volume of sample injected was $1 \mu l$ and split injection (50:1 ratio) was used. The flow rate of the carrier gas was $1 \mathrm{ml} / \mathrm{min}$. The temperature was $280^{\circ}$ for the injector and $300^{\circ}$ for the detector. The following temperature program was used for the oven: $100^{\circ}$ at standby; increased at $7.5^{\circ} / \mathrm{min}$ from $100^{\circ}$ to $190^{\circ}$; increased at $20^{\circ} / \mathrm{min}$ from $190^{\circ}$ to $275^{\circ}$; held at $275^{\circ}$ for $10 \mathrm{~min}$; increased at $20^{\circ} / \mathrm{min}$ from $275^{\circ}$ to $295^{\circ}$; and finally held at $295^{\circ}$ for $10 \mathrm{~min}$. The total run time was $37.3 \mathrm{~min}$. Data were collected using a Hewlett Packard 3393A integrator.

\section{Calculation of the rate of absorption of phenylpropionic acid and cyclohexanecarboxylic} acid from the rumen

The fractional rate of disappearance of PPA or CHCA $(k)$ was measured by fitting the data of ruminal concentration (C) of PPA or CHCA into a single exponential function of time ( $t), C=A+B e^{-k t}$. The ' $k$ ' is the sum of the fractional rate of absorption and that of outflow from the rumen. The liquid outflow rate was estimated by the disappearance of 
Cr-EDTA. The data of disappearance of $\mathrm{Cr}$ were fitted into a two-compartment model $C_{m}=B_{1} e^{-u_{1} t}+B_{2} e^{-u_{2} t}$, where $C_{m}$ is the concentration of $\mathrm{Cr}$ in the rumen fluid. The fitted parameters $\mathrm{B}_{1}, \mathrm{~B}_{2}, u_{1}$ and $u_{2}$ do not directly refer to any physical terms. However, based on these parameters and the amount of Cr-EDTA dosed, the fractional liquid outflow rate and rumen liquid volume can be calculated. The calculation was done according to Czerkawski (1986). The curve-fitting was performed using the computer program MLP (Ross, 1987).

\section{Statistical analysis}

Two-way ANOVA according to a randomized-block design was performed on the data of urinary excretion of BA to compare the eight treatments. The models for the partitioning of variance included the effects of PPA and CHCA infusions, of PPA $\times$ CHCA interaction, and animal variation. The response of urinary excretion of total BA to the infusion of PPA alone or PPA plus CHCA was examined by simple and multiple regression analysis. The statistical calculations were performed with the aid of computer program Genstat 5.31 (Genstat 5 Committee, 1993).

\section{RESULTS}

\section{Animal health}

Rumen fluid $\mathrm{pH}$ and osmolality remained rather steady (pH 6.6 (SD 0.3) and osmolality 264 (SD 18 ) $\mathrm{mOsmol} / \mathrm{kg}$ ). The animals were generally in good health and gained weight by 3.38 (SD 2.02) kg over the experiment. However there was occasional scouring in all animals, in which case a dose of the intestinal protectant Stat ${ }^{\circledR}$ (Intervet, Cambridge, Cambs.) as an emulsion was administered via the abomasal catheter. When scouring persisted for more than $2 \mathrm{~d}$, blood samples were collected to check the possibility of sub-clinical infections and the animals were treated with antibiotics. There was no sign of the toxicity that has been reported in goats (Ringer, 1911) and sheep (Martin, 1966) given high doses of BA.

\section{Ruminal liquid volume, outflow rates and absorption rates}

Measurements of the rates of disappearance from the rumen of $\mathrm{Cr}$, PPA and CHCA are shown in Table 2. The fractional outflow rate of liquid averaged $0.062(\mathrm{SD} 0.005) / \mathrm{h}$. Rumen liquid volume averaged 10.5 (SD 1.92) litres. The rates of disappearance of either PPA $(0.84$ (SD 0.29)/h) or CHCA $(0.94$ (SD 0.28)/h) were much higher than the liquid outflow rate. The calculated rates of absorption from the rumen were 0.78 (SD 0.29 )/h for PPA and 0.88 (SD 0.28)/h for CHCA; there was a marked difference between sheep.

\section{Urinary excretion of phenylpropionic acid and cyclohexanecarboxylic acid-related metabolites}

Table 3 shows the results of mean urinary excretion of PPA and CHCA-related metabolites for each experimental treatment. A trace of CHCA was detected in the urine (highest daily output $0.35 \mathrm{mmol} / \mathrm{d}$ ) when CHCA was infused. Small quantities of PPA (highest daily output $0.33 \mathrm{mmol} / \mathrm{d}$ ) were detected when $16 \mathrm{mmol}$ PPA/d plus $8-16 \mathrm{mmol}$ CHCA/d were infused (treatments 7-8). Small quantities of CA (highest daily output $1 \mathrm{mmol} / \mathrm{d}$ ) were detected when $24 \mathrm{mmol}$ PPA/d was infused alone or when PPA was infused together with CHCA (treatments 4-8). 


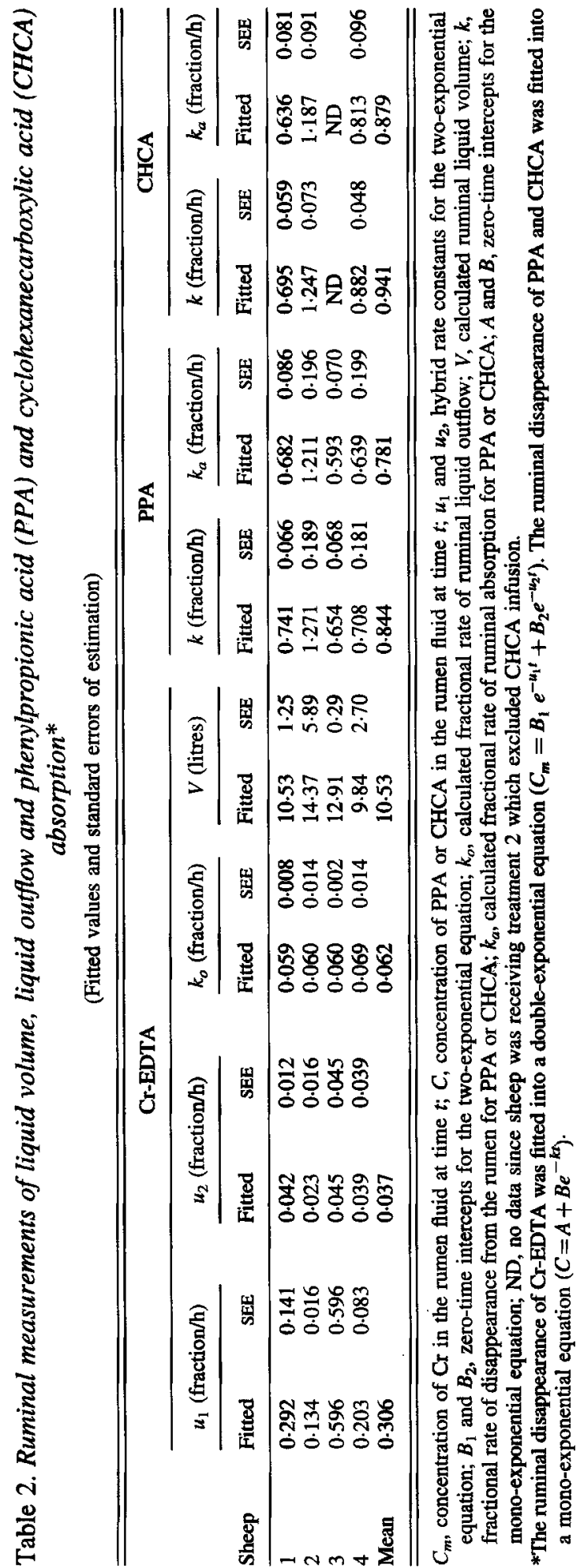


Table 3. Urinary outputs of hippuric acid (HA), benzoic acid $(B A)$, phenylpropionic acid $(P P A)$, cyclohexanecarboxylic acid (CHCA) and aromatic amino acids-related metabolites in sheep given an infusion of PPA with or without CHCA $\dagger$

(Values are means of twelve observations for treatment 1 and four observations for the other treatments)

\begin{tabular}{|c|c|c|c|c|c|c|c|c|c|c|c|c|}
\hline \multirow[b]{2}{*}{ Treatment } & \multicolumn{2}{|c|}{$\begin{array}{c}\text { Infused } \\
\text { (mmol/d) }\end{array}$} & \multicolumn{10}{|c|}{ Excreted (mmol/d) } \\
\hline & PPA & $\mathrm{CHCA}$ & CHCA & PPA & $\mathrm{CA}$ & HA & BA & Total BAf & PUA & PA & Total PA§ & $\mathrm{PC}$ \\
\hline 1 (all periods) & 0 & 0 & 0.00 & 0.00 & 0.00 & 0.22 & 0.00 & 0.22 & 3.40 & 0.88 & $4 \cdot 28$ & 1.05 \\
\hline 2 & 8 & 0 & 0.00 & 0.00 & 0.00 & $5 \cdot 16$ & 1.02 & 6.18 & 3.45 & 0.97 & $4 \cdot 42$ & 0.28 \\
\hline 3 & 16 & 0 & 0.00 & 0.00 & 0.00 & 9.99 & 2.09 & 12.08 & 3.87 & 0.98 & 4.84 & 0.33 \\
\hline 4 & 24 & 0 & 0.00 & 0.00 & 0.22 & 15.94 & 3.10 & 19.04 & 3.71 & 0.80 & 4.51 & 0.15 \\
\hline 5 & 8 & 8 & 0.04 & 0.00 & 0.23 & $11 \cdot 15$ & 2.08 & $13 \cdot 23$ & 3.67 & 0.83 & 4.50 & 0.19 \\
\hline 6 & 8 & 16 & 0.07 & 0.00 & 0.23 & $15 \cdot 67$ & 3.07 & 18.74 & 3.72 & 0.91 & 4.63 & 0.16 \\
\hline 7 & 16 & 8 & 0.05 & 0.02 & 0.51 & 16.55 & 3.00 & 19.55 & $4 \cdot 12$ & 0.79 & 4.91 & 0.61 \\
\hline 8 & 16 & 16 & 0.08 & 0.01 & 0.49 & $20-66$ & 4.78 & 25.43 & 3.93 & 0.90 & 4.82 & 0.10 \\
\hline Pooled SED & & & 0.03 & 0.01 & 0.07 & 0.87 & 0.76 & 0.48 & 0.31 & 0.13 & 0.34 & 0.27 \\
\hline Animal & & & NS & NS & NS & NS & NS & NS & NS & NS & NS & NS \\
\hline Treatment & & & NS & NS & $* * *$ & $* * *$ & $* * *$ & $* * *$ & NS & NS & NS & NS \\
\hline
\end{tabular}

CA, cinnamic acid; PUA, phenylaceturic acid; PA, phenylacetic acid; PC, $p$-cresol

$* * * P<0.001$.

$\uparrow$ For details of procedures, see pp. 579-582.

$\ddagger$ Total BA $=$ HA + BA.

$\S$ Total PA $=$ PUA + PA.

During the first control period, no free BA nor HA was detected in the urine of any animal. During the second and third control periods, no free BA and only small amounts of HA were detected in sheep 2 and 4 but none in sheep 1 and 3. The average excretions of the two periods were 0.62 (SD 0.32) and 0.52 (SD 0.31) mmol/d for sheep 2 and 4 respectively and the daily excretion decreased with time. The overall (four sheep) mean for the HA excretion was 0.22 (SD 0.33) $\mathrm{mmol} / \mathrm{d}$. When PPA and CHCA were infused, both free BA and HA were excreted in the urine, with HA comprising 0.85 (SD 0.05) of the total BA, i.e. the molar sum of $\mathrm{HA}$ and free BA. When urine samples were hydrolysed in $6 \mathrm{M}-\mathrm{HCl}$, there was no increase in the concentration of total BA, indicating the absence of the glucuronic acid conjugate of BA. In the present paper, total BA therefore refers to the sum of free BA and HA.

Fig. 2 shows the response of total BA excretion in urine to the levels of infusion of PPA alone or together with CHCA. There was no significant difference $(P>0.05)$ between sheep in the response. On examination of the curvilinearity of the response of total BA output to the input of PPA and CHCA, ANOVA showed that total BA was linearly correlated with either PPA or CHCA with no significant quadratic effect $(P>0.05)$. Equation $(1)$ describes the response of total BA output in urine $(Y, \mathrm{mmol} / \mathrm{d})$ to the amount of PPA $(X, \mathrm{mmol} / \mathrm{d})$ infused when no CHCA was present (based on data from treatments 1-4):

$$
\begin{array}{r}
Y=0.143(\text { SE } 0.143)+0.774(\text { SE } 0.012) X \\
\left(r^{2} 0.995, \text { RSD } 0.523, n 24, P<0.001\right) .
\end{array}
$$

The following equation describes the response of total BA output in urine $(Y, \mathrm{mmol} / \mathrm{d})$ to the amounts of PPA $(X, \mathrm{mmol} / \mathrm{d})$ and CHCA $(Z, \mathrm{mmol} / \mathrm{d})$ infused (based on data from all treatments):

$$
\begin{gathered}
Y=0.163(\operatorname{SE} 0.193)+0.782(\operatorname{SE} 0.015) X+0.798(\operatorname{SE} 0.019) Z \\
\left(r^{2} 0.994, \text { RSD } 0.729, n 40, P<0.001\right) .
\end{gathered}
$$




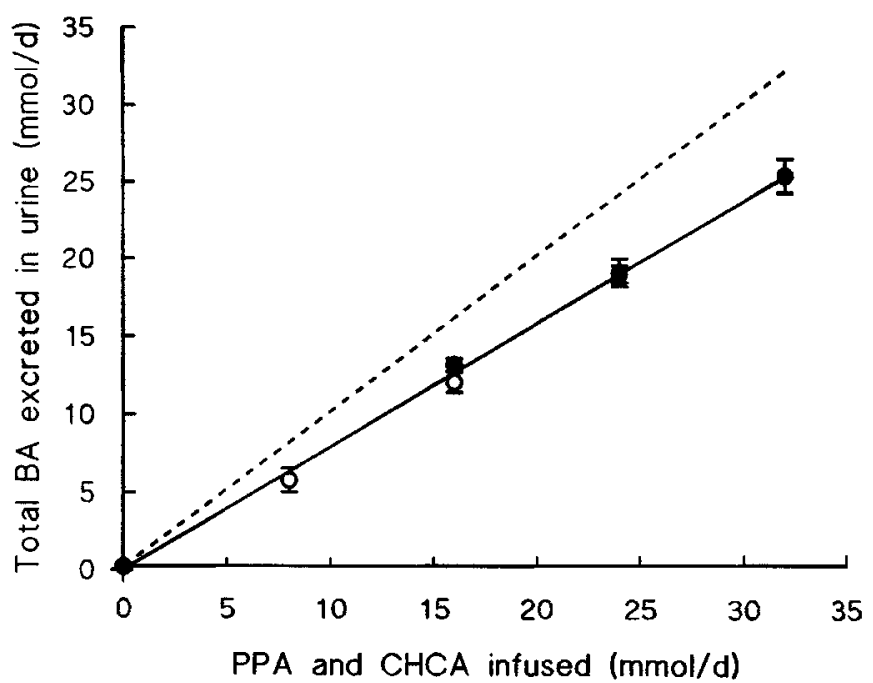

Fig. 2. The urinary excretion of the total benzoic acid (BA) in sheep given ruminal infusion of 3-phenylpropionic acid (PPA) alone $(O)$ or together with cyclohexanecarboxylic acid (CHCA) (O). Values are means for four sheep, with standard deviations represented by vertical bars. $(\longrightarrow)$ Fitted line $(Y=0.144+0.789 P)$, where $Y$ is output of total BA, $P$ is total amount of precursors infused. (-- - ), Expected output if recovery were complete $(Y=P)$.

Equations (1) and (2) indicate that the recoveries of the infused PPA, as total BA in urine, were 0.77 and $0.78 \mathrm{PPA}$ infusion without or with CHCA present. The two values were not significantly different $(P>0 \cdot 05)$. There was therefore no interaction between the PPA and CHCA infusions in the output of total BA. ANOVA also showed no significant $(P>0.05)$ interaction between the PPA and CHCA infusions in their effect on the output of total BA. Equation (2) indicates that the estimated recoveries of the infused PPA and CHCA, as total BA in urine, were 0.78 and 0.80 respectively. The difference between PPA and CHCA in their recovery factors was not significant. Therefore, the inputs of PPA and CHCA were considered as a single variable. The response of total BA output in urine ( $Y$, $\mathrm{mmol} / \mathrm{d})$ to the infusion of the sum of PPA and CHCA $(P, \mathrm{mmol} / \mathrm{d}) \mathrm{can}$ be described as:

$$
\begin{gathered}
Y=0.144(\text { SE } 0.189)+0.789(\text { SE } 0.010) P \\
\left(r^{2} 0.994, \text { RSD } 0.723, n 40, P<0.001\right) .
\end{gathered}
$$

\section{Excretion of metabolites of aromatic amino acids}

Table 3 also lists the daily urinary excretion of known aromatic acid metabolites such as phenylacetic acid, its glycine conjugate phenylaceturic acid, and $p$-cresol. The daily output of total phenylacetic acid was rather constant (4.61 (SD 0.23) mmol/d) for all treatments. As with BA, about 0.82 of the total phenylacetic acid was excreted in the urine as its glycine conjugate. The phenol $p$-cresol was in conjugated form as it was not present in unhydrolysed urine. However, a large variation in p-cresol was noted, probably due to variable losses of this phenol by volatilization during hydrolysis.

\section{Faecal excretion of phenylpropionic acid and cyclohexanecarboxylic acid-related metabolites}

CHCA and CA were not detected in any of the faecal samples. Only trace amounts of other acids were found in faeces. The range of individual measurements recorded was: 
Table 4. Faecal output of hippuric acid (HA), benzoic acid (BA), phenylpropionic acid (PPA), cyclohexanecarboxylic acid (CHCA) and aromatic amino acids-related metabolites in sheep given an infusion of PPA with or without $\mathrm{CHCA}^{*}$

(Values are means of twelve observations for treatment 1 and four observations for the other treatments)

\begin{tabular}{|c|c|c|c|c|c|c|c|c|c|c|c|}
\hline \multirow[b]{2}{*}{ Treatment } & \multicolumn{2}{|c|}{$\begin{array}{l}\text { Infused } \\
(\mathrm{mmol} / \mathrm{d})\end{array}$} & \multicolumn{9}{|c|}{ Output in faeces $(\mu \mathrm{mol} / \mathrm{d})$} \\
\hline & PPA & CHCA & CHCA & PPA & CA & HA & BA & Total BAt & PUA & PA & Total PAf \\
\hline 1 & 0 & 0 & 0.0 & 7.8 & 0.0 & 0.3 & $17 \cdot 0$ & $17 \cdot 3$ & 3.7 & 26.9 & $30 \cdot 6$ \\
\hline 2 & 8 & 0 & 0.0 & 10.9 & 0.0 & 2.6 & 14.4 & $17 \cdot 0$ & $3 \cdot 2$ & 29.9 & $33 \cdot 1$ \\
\hline 3 & 16 & 0 & 0.0 & 11.6 & 0.0 & 0.0 & $15 \cdot 0$ & $15 \cdot 0$ & 12.6 & $25 \cdot 1$ & 37.7 \\
\hline 4 & 24 & 0 & 0.0 & $8 \cdot 3$ & 0.0 & 0.0 & $18 \cdot 1$ & $18 \cdot 1$ & 0.0 & $43 \cdot 0$ & 43.0 \\
\hline 5 & 8 & 8 & 0.0 & $13 \cdot 3$ & 0.0 & 0.0 & 13.7 & 13.7 & 7.7 & $32 \cdot 0$ & 39.7 \\
\hline 6 & 8 & 16 & 0.0 & $7 \cdot 1$ & 0.0 & 0.0 & 11.2 & $11 \cdot 2$ & $2 \cdot 3$ & 38.2 & 40.4 \\
\hline 7 & 16 & 8 & 0.0 & 5.0 & 0.0 & 0.0 & 14.2 & $14 \cdot 2$ & 0.7 & 23.4 & 24.1 \\
\hline 8 & 16 & 16 & 0.0 & 12.1 & 0.0 & 3.8 & 15.9 & 19.7 & 6.9 & 27.9 & 34.9 \\
\hline Pooled SED & & & 0.0 & 4.7 & 0.0 & 1.5 & $6 \cdot 3$ & 6.6 & $5 \cdot 5$ & 1.5 & 15 \\
\hline Animal & & & NS & NS & NS & NS & NS & NS & NS & NS & NS \\
\hline Treatment & & & NS & NS & NS & NS & NS & NS & NS & NS & NS \\
\hline
\end{tabular}

CA, cinnamic acid; PUA, phenylaceturic acid; PA, phenylacetic acid.

*For details of procedures, see pp. 579-582.

$\uparrow$ Total BA $=\mathbf{H A}+\mathbf{B A}$.

$\ddagger$ Total PA $=$ PUA + PA.

2-30 $\mu \mathrm{mol} / \mathrm{d}$ for PPA, 2-60 $\mu \mathrm{mol} / \mathrm{d}$ for BA and 0-100 $\mu \mathrm{mol} / \mathrm{d}$ for phenylacetic acid. The mean faecal outputs of PPA and CHCA-related metabolites for each experimental treatment are listed in Table 4.

\section{DISCUSSION}

\section{Absorption of phenylpropionic acid and cyclohexanecarboxylic acid from the rumen}

Cr-EDTA is commonly used as a liquid marker for the measurement of rumen liquid outflow rate. Although Goodall \& Kay (1973) noted that some Cr-EDTA was absorbed from the digestive tract and excreted in the urine in sheep, the studies of Dobson et al. (1976) confirmed that the absorption of Cr-EDTA from the rumen epithelium only took place when rumen fluid was hyperosmotic relative to plasma. In the present work, the rumen fluid was slightly hypo-osmotic relative to plasma, and thus absorption of Cr-EDTA from the rumen was not expected. Indeed, no colour change of urine was visible after dosing with Cr-EDTA.

As shown in Table 2, there was considerable variation among the four observations in the rates of disappearance of PPA and CHCA from the rumen, but not in the rates of liquid outflow. Therefore, the variability rested in the rates of absorption of PPA and CHCA. Since the measurement of absorption was performed only once per sheep, there was insufficient information to indicate whether the observed variability was animal-related or treatment-related. In recognition of the limited number of observations, the average rates of PPA and CHCA absorption obtained in this work should only be taken as an approximate. Despite this constraint, the results categorically showed that PPA and CHCA rapidly disappeared from the rumen in comparison with the liquid marker.

It is interesting to note that PPA and CHCA were absorbed from the rumen rapidly, considering that weak electrolytes normally move across epithelia predominantly by diffusion in their unionized form. In the slightly acidic conditions ( $\mathrm{pH} \mathrm{6.5)}$ of the rumen 
fluid, it can be calculated that 0.99 of PPA $\left(\mathrm{p} K_{\mathrm{a}}=4.4\right)$ and 0.98 of CHCA (pK $\left.K_{\mathrm{a}}=4.9\right)$ was in dissociated form. Similarly VFA, which are also present in dissociated form, are absorbed rapidly from the rumen (Weekes, 1976). It is possible that the rapid absorption of PPA and CHCA from the rumen observed in this work may involve a mechanism similar to that for the absorption of VFA.

In interpreting the results of disappearance of $\mathrm{Cr}$ from the rumen, a simple exponential (one-compartment) model was initially used. However, the fitted asymptote was significantly different from zero indicating the presence of a second compartment. Therefore a two-compartment model was finally used and this also improved the fitting (lower residual error). The use of compartmental analysis to describe the dynamics of ruminal disappearance of single-dosed markers is well reported (e.g. Czerkawski, 1986). The second compartment could refer to an unstirred layer of fluid in contact with the rumen wall which would attract the negatively charged Cr-EDTA complex. The disappearance of PPA and CHCA from the rumen was fitted into a one-compartment model, because the disappearance was so rapid that the concentration reached zero at $4 \mathrm{~h}$ and thus there were insufficient data points (five data points) to verify the occurrence of a two-compartment model.

Since the faecal excretion of PPA, CHCA and their metabolites was negligible and these chemicals are resistant to microbial degradation that could occur in the hindgut, it is reasonable to assume that the absorption of the PPA and CHCA infused was complete. There were no direct measurements of the relative importance of the sites of absorption. However, based on the estimated fractional rate of absorption from the rumen $\left(k_{a}\right)$ and that of liquid outflow $\left(k_{o}\right)$, we estimate that about 0.92 (calculated as $k_{a} /\left(k_{a}+\mathrm{k}_{o}\right)$ ) of the PPA and CHCA infused into the rumen was absorbed directly from the rumen.

\section{Faecal excretion of benzoic acid and its precursors}

The observation in the present study that insignificant amounts of BA and its precursors were excreted in the faeces was expected. Xenobiotic compounds may appear in the faeces mainly due to biliary excretion. However, biliary excretion in mammals becomes significant for a compound only when its $M_{\mathrm{r}}$ is above 325 (Hirom et al. 1972). Even as glucuronide conjugates, PPA, CHCA and their metabolites do not exceed that threshold $M_{\mathrm{r}}$, and it is therefore not expected that they appear in the faeces in significant amounts. It is interesting to note that the acids detected in faeces were mainly in the free form, which may reflect the deconjugative activity of micro-organisms in the hindgut.

\section{Excretory metabolites of aromatic amino acids}

In the present study, casein infused into the abomasum was the exogenous source of amino acids for sheep. Since efficient small-intestinal absorption of amino acids resulting from digested casein would have prevented, to a large extent, hindgut microbial metabolism of phenylalanine and tyrosine, it is probable that the small amounts of phenylacetic acid and $p$-cresol found in the urine were mainly of endogenous origin. Both phenylacetic acid and $p$-cresol, known as excretion products of phenylalanine and tyrosine respectively, appear in the urine of sheep even under fasting conditions (Martin, 1978). In fact, the levels of total urinary phenylacetic acid observed in the present work $(4-5 \mathrm{mmol} / \mathrm{d})$ were similar to those reported by Martin (1973) for fasted sheep. 


\section{Forms of benzoic acid excreted in the urine}

BA can potentially be excreted in the urine in three forms: free BA, HA and benzoylglucuronide (the conjugate with glucuronic acid). The conjugation of BA (and indeed other xenobiotics) has two advantages: (1) attenuation of its toxic strength and (b) increase of its water solubility thus making it more readily excreted in the urine. It was observed in the present study that 0.85 of the total BA in the urine was in the form of HA. This proportion was within the range of values for normally-fed sheep reported by other authors (Giráldez et al. 1993).

In the present study, urine samples were hydrolysed in $6 \mathrm{M}-\mathrm{HCl}$ thereby converting all conjugates to their free acids. No increment in BA concentration was observed compared with the sum of free BA and HA in unhydrolysed urine, suggesting that very little or no benzoylglucuronide was present in the urine. However, our observation may have been an artifact of the acidic condition used to preserve the urine samples. The glucuronide conjugates of carboxylic acids are unstable under extreme $\mathrm{pH}$ conditions (J. Caldwell, personal communication) and it is therefore probable that hydrolysis of benzoylglucuronide to free BA could have occurred in the urine before analysis. If it is assumed that no free BA was actually excreted in the urine, then potentially about 0.15 of the total BA could have been present as glucuronide conjugate.

The relative proportions of the glycine and glucuronide conjugates to be excreted in the urine appear to be determined by the input of the free acid (Hutt \& Caldwell, 1990). Martin (1966) dosed sheep with $79-444 \mathrm{mmol} \mathrm{BA} / \mathrm{d}$ and observed that by increasing the dose the proportion of total urinary BA as benzoylglucuronide was higher. This feature may be explained by the characteristics of the enzyme systems involved. The enzymes for glycine conjugation tend to be a high-affinity but low-capacity system, and those for glucuronic acid conjugation a low-affinity but high-capacity system (Hutt \& Caldwell, 1990). The proportion of total urinary BA as HA was relatively stable in the range of levels of BA precursors infused in this work $(8-32 \mathrm{mmol} / \mathrm{d})$. When no BA precursors were infused (control treatment) the only form of BA excreted in the urine was HA.

\section{Urinary recovery of infused phenylpropionic acid and cyclohexanecarboxylic acid}

No free BA was found in the urine of all four animals during the three control periods. Small amounts of HA were found in the urine of two animals during the last two control periods and the daily output showed a trend of decreasing with time. The results imply that there was practically no endogenous contribution of either HA or BA. The trace amount of HA noted was the residual from the previous treatments in which large amounts of BA precursors were infused. Martin (1973) reported that total BA excretion in the urine of sheep fell from 44-159 mmol/d with roughage feeding to $1 \mathrm{mmol} / \mathrm{d}$ between days 5 and 10 of fasting (Martin, 1973). Grümer (1961) detected a small amount of urinary BA arising from a minor pathway of phenylalanine catabolism in tissues in man. However, the results of Martin (1973) indicated that in ruminants the metabolism of aromatic amino acids, either in tissues or in the digestive tract (by rumen microbes), contributed little to the urinary BA excretion. The present work also confirms Martin's (1973) observation.

Results from in vitro assays in our laboratory (J. H. Pagella, X. B. Chen, W. J. Shand and E. R. Ørskov, unpublished results) have shown that the ruminal production of CHCA is quantitatively unimportant compared with the production of PPA, indicating that PPA is the main precursor of BA. Therefore, the treatments of the experiment were designed with an emphasis to illustrate the quantitative response of BA excretion to PPA absorption in the 
presence or absence of CHCA. Since CHCA was infused together with PPA, the effect of CHCA infusion may have been confounded by the presence of PPA and the response observed would therefore be applicable only to situations where PPA is also present. However, when animals are fed with cellulosic feeds, PPA is always present, with or without CHCA, as a source of BA.

Results of the present work show that total BA excretion in the urine responded linearly to the amounts of PPA and CHCA infused. The recoveries of PPA and CHCA as BA in urine were constant over the range of infusion levels and can be regarded as practically identical $(0.79)$. The urinary recovery of total BA after dosing normally-fed sheep with BA and its precursors has been assessed by other authors (see Table 5). BA dosed at levels between 39 and $442 \mathrm{mmol} / \mathrm{d}$ was readily excreted in the urine within $24 \mathrm{~h}$, indicating that ruminants are very efficient at eliminating BA by this route. Martin (1982a) gave sheep ruminal or abomasal infusions of PPA, CA or CHCA (each at about $40 \mathrm{mmol} / \mathrm{d}$ ). The urinary recoveries of the infused compounds as total BA were $0.96-1.05$ for PPA, $0.70-0.79$ for $\mathrm{CA}$ and $0.41-0.43$ for CHCA. The route of dosing did not affect significantly the urinary recoveries as total BA. The recovery of PPA in the present experiment was lower than found by Martin (1982a); the recovery of CHCA, however, was markedly greater. It should be pointed out that Martin's recovery values were based on single-point measurements, and faecal excretion was not measured.

The recovery of infused PPA and CHCA as urinary BA was incomplete. After absorption from the gut, PPA is converted to BA by $\beta$-oxidation involving intermediate metabolites such as CA, 3-hydroxy-3-phenylpropionic acid and 3-keto-3-phenylpropionic acid (Scheline, 1978). The aromatization of CHCA to form BA involves intermediates such as cyclohexene-1-carboxylic acid (Brewster et al. 1977). In the present study, only the intermediate metabolite CA was determined. There was virtually no PPA excreted in the urine, and the urinary outputs of $\mathrm{CA}$ and CHCA observed were minute (Table 3). Only up to 0.06 of the infused PPA was excreted as CA and up to 0.03 of the infused CHCA was excreted as such in the urine, proportions similar to those reported by Martin (1982a) when infusing the same acids in sheep. Even taking this into account, from 0.10 to 0.15 of the infused PPA or CHCA was still unaccounted for in the present study. Whether the missing fraction could be explained by the presence of other metabolites in the urine is not clear.

Table 5. A summary of results reported in the literature on the recovery of benzoic acid $(B A)$ and its precursors dosed to ruminants

\begin{tabular}{lclccc}
\hline \hline Acid dosed & Species & Dosing route & Dose (mmol/d) & \% Dose as urine BA & Reference \\
\hline BA & goat & oral & $57-155$ & $85^{*}$ & Ringer (1911) \\
& cattle & oral & 56 & $69^{*}$ & Ringer (1911) \\
& sheep & abomasal & $79-442$ & 17 & Martin (1966) \\
& cattle & oral & 53 & $98 \dagger$ & Kreula et al. (1978) \\
& sheep & ruminal & 40 & 90 & Martin (1982a \\
& sheep & abomasal & $39-43$ & 88 & Martin (1982a) \\
CHCA & sheep & ruminal & 37 & 43 & Martin (1982a) \\
& sheep & abomasal & 37 & 41 & Martin (1982a) \\
PPA & sheep & ruminal & 40 & 96 & Martin (1982a) \\
& sheep & abomasal & 43 & 105 & Martin (1982a) \\
CA & sheep & ruminal & 39 & 70 & Martin (1982a) \\
& sheep & abomasal & $40-43$ & 79 & Martin (1982a) \\
\hline \hline
\end{tabular}

CHCA, cyclohexanecarboxylic acid; PPA, 3-phenylpropionic acid; CA, cinnamic acid.

* Only hippuric acid measured.

$\dagger$ Measured by radioactive $\left[{ }^{14} \mathrm{C}\right] \mathrm{BA}$. 
Martin (1982a) did not find 3-hydroxy-3-phenylpropionic acid in the urine of sheep even after infusion of either PPA or CA.

The presence of metabolic routes for PPA and CHCA other than that leading to the formation of BA should not be ruled out although they have not yet been confirmed. Ethylbenzene and benzaldehyde (Larick \& Turner, 1990) and methylbenzaldehyde (Hedrick et al. 1980), found as constituents of the carcass of grazing cattle, may originate from PPA. Carboxyl-substituted xenobiotics like PPA and CHCA can also be incorporated into lipids following the normal metabolic pathways of fatty acids. The elongation of the side-chain of CHCA may occur since the related fatty acid 11-cyclohexylundecanoic acid has been reported as a constituent of perinephric fat in sheep (Hansen \& Gerson, 1967) and butter (Schogt \& Haverkamp-Begemann, 1965). A final metabolic route to be considered is the complete catabolism of PPA and CHCA to $\mathrm{CO}_{2}$. While this is possible for CHCA (Brewster et al. 1977), the oxidative cleavage of the PPA aromatic ring would be biochemically more restricted. In the present work, the quantitative importance of the mentioned alternative metabolic routes was not assessed.

Some factors delay the elimination of PPA and CHCA and their products from the body. Secretion of BA and its precursors into the gut via saliva or directly across the rumen is possible, since PPA $(0.05 \mathrm{mmol} / \mathrm{l})$ was detected in saliva of sheep (Scott $e t$ al. 1964) and the ruminal epithelium is bidirectionally permeable to aromatic acids (Jenkins et al. 1975). Secretion into the gut via biliary secretion is also possible. The fact that PPA, CHCA and $\mathrm{BA}$ are stable and are readily absorbed from the rumen and posterior gut compartments, indicates that if these compounds were secreted into the gut they would then be reabsorbed and induce no net loss from the system. The negligible output of these compounds in the faeces confirms that secretion of BA or its precursors into the gut was not the main reason for the incomplete recovery of the infused PPA and CHCA.

\section{Implications}

Despite the uncertainty arising from the incomplete recovery of the infused PPA and CHCA, the results of the present study conclusively showed that the dose-response of BA excretion in the urine to the uptake of PPA or CHCA was linear and consistent among animals. Based on this relationship, the uptake of PPA and CHCA from the rumen may be estimated from the urinary BA output. Among PPA and CHCA, PPA is quantitatively the predominant precursor of BA. Since PPA is produced from phenolic precursors released in the rumen during the microbial degradation of plant cell-wall constituents, the information from this work is useful in two ways. First, it provides the basis for using BA excretion as an indicator to compare the extent of degradation of a particular cellulosic feed subjected to different treatments. Second, if the potential production rate of PPA (or PPA + CHCA) for a particular cellulosic feed can be quantified, there is a possibility of estimating cellulosic feed intake based on BA excretion.

\section{Conclusions}

The BA excreted in the urine was almost exclusively of dietary (exogenous) origin. PPA and CHCA were rapidly absorbed from the rumen. Absorption of PPA and CHCA from the whole digestive tract was complete. Over the physiological range of uptake of PPA and CHCA, a constant proportion (0.79) of the absorbed PPA or CHCA was excreted in the urine as total BA, which was mainly in the form of HA. It is not clear what happened to the fraction of PPA and CHCA infused that was not recovered in urine and faeces, but it is speculated that alternative metabolic routes to the well established ones may account for it. 
Although further studies are required to confirm this speculation, results of the present study show that urinary total BA is a potential estimator of the absorption of PPA + CHCA produced in the rumen. This work contributes to a better understanding of the quantitative aspect of BA metabolism in ruminants.

J. H. Pagella thanks the Consejo Nacional de Investigaciones Científicas y Técnicas (CONICET) of Argentina and the Universidad Nacional de La Pampa for financial support. The authors are grateful to Dr M. Franklin for advice on statistical analysis of the data, Dr R. N. B. Kay for criticism on the manuscript and SOAFD for financial support.

\section{REFERENCES}

Agricultural Research Council (1980). The Nutrient Requirements of Ruminant Livestock. Technical Review by an Agricultural Research Council Working Party. Farnham Royal: Commonwealth Agricultural Bureau.

Binnerts, W. T., van't Klooster, A. T. \& Frens, A. M. (1968). Soluble chromium indicator measured by atomic absorption in digestion experiments. Veterinary Record 82, 470.

Brewster, D., Jones, R. R. \& Parke, D. V. (1977). The metabolism of cyclohexanecarboxylate in the rat. Biochemical Journal 164, 595-600.

Caldwell, J. (1989). Xenobiotic metabolism: an introduction. In Intermediary Xenobiotic Metabolism in Animals: Methodology, Mechanisms and Significance, pp. 3-12 [D. H. Hutson, J. Caldwell and G. D. Paulson, editors]. London: Taylor and Francis.

Chen, X. B., Mejía, A. T., Pagella J. H., Kyle, D. J. \& Ørskov, E. R. (1993). Urinary excretion of purine derivatives and benzoic acid as an indication of microbial protein supply and cellulosic feed intake in sheep. In Proceedings of the 22 Rumen Function Conference, vol. 22, p. 15. Chicago, IL: Agricultural Research Service and US Department of Agriculture.

Chen, X. B., Pagella, J. H., Bakker, M. L. \& Parra, O. (1996). Determination of aromatic metabolites in ruminant urine by high performance liquid chromatography. Joumal of Chromatography B 682, 201-208.

Czerkawski, J. W. (1986). Introduction to Rumen Studies. Oxford: Pergamon Press.

Dobson, A., Sellers, A. F. \& Gatewood, V. H. (1976). Dependence of Cr-EDTA absorption from the rumen on luminal osmotic pressure. American Journal of Physiology 231, 1595-1600.

Genstat 5 Committee (1993). Genstat 5 Release Reference Manual. Oxford: Oxford University Press.

Giráldez, F. J., Zorita, E. \& Peláez, R. (1993). Urinary hippuric acid excretion as related to changes in cell wall digestibility due to variation in degradable protein supply. In Animal Production in Developing Countries, Occasional Publication no. 16, pp. 192-193 [M. Gill, E. Owen, G. E. Pollot and T. L. J. Lawrence, editors]. Midlothian: British Society of Animal Production.

Goodall, E. D. \& Kay, R. N. B. (1973). The use of the chromium complex of ethylenediaminetetra-acetic acid for studies of digestion in sheep. Proceedings of the Nutrition Society 32, 22A-23A.

Grümer, H. D. (1961). Formation of hippuric acid from phenylalanine labelled with carbon-14 in phenylketonuric subjects. Nature 189, 63-64.

Hansen R. P. \& Gerson, T. (1967). The isolation of 11-cyclohexylundecanoic acid from sheep perinephric fat. Journal of the Science of Food and Agriculture 18, 225-227.

Hedrick, H. B., Bailey, M. E., Dupuy, H. P. \& Legendre, M. G. (1980). Relationship between volatile compounds in fat from forage and grain-fed beef and sensory characteristics of steaks and roasts. In Proceedings of the 26 European Meeting of Meat Research Workers Volume of Abstracts, p. 307. Colorado Springs: American Meat Science Association.

Hirom, P. C., Millburn, P., Smith, R. L. \& William, R. T. (1972). Species variation in the threshold molecularweight factor for the biliary excretion of organic anions. Biochemical Journal 129, 1071-1077.

Hutt, J. H. \& Caldwell, J. (1990). Amino acid conjugation. In Conjugation Reactions in Drug Metabolism: An Integrated Approach, pp. 273-305 [G. J. Mulder, editor]. London: Taylor and Francis.

Jenkins, W. L., Davis, L. E. \& Boulos, B. M. (1975). Transfer of drugs across the ruminal wall in goats. American Journal of Veterinary Research 36, 1771-1776.

Kreula, M., Raumaramaa, A. \& Tengengren, M. (1970). On the metabolism of benzoic acid by cows on purified protein-free and low-protein feed. Journal of the Scientific Agricultural Society of Finland 50, 177-181.

Larick, D. K. \& Turner, B. E. (1990). Headspace volatile and sensory characteristics of ground beef from foragefed and grain-fed heifers. Journal of Food Science 54, 649-654.

MacLeod, N. A., Corrigal, W., Stirton, R. A. \& Ørskov, E. R. (1982). Intragastric infusion of nutrients in cattle. British Journal of Nutrition 47, 547-552.

Martin, A. K. (1966). Metabolism of benzoic acid by sheep. Journal of the Science of Food and Agriculture 17, 496-500. 
Martin, A. K. (1969). Urinary excretion of aromatic acids by sheep given diets containing different amounts of protein and roughage. British Journal of Nutrition 23, 389-399.

Martin, A. K. (1973). Urinary aromatic excretion by fed and fasted sheep in relation to protein metabolism in the rumen. British Joumal of Nutrition 30, 251-267.

Martin, A. K. (1978). The metabolism of aromatic compounds in ruminants. In The Hannah Research Institute, 1928-1978, Essays of the Scientific Work of the Institute, pp. 148-163 [J. H. Moore and J. A. F. Rook, editors]. Ayr: Hannah Research Institute.

Martin, A. K. (1982a). The origin of urinary aromatic compounds excreted by ruminants 1 . The metabolism of quinic, cyclohexanecarboxylic and non-phenolic aromatic acids to benzoic acid. British Journal of Nutrition 47, 139-154.

Martin, A. K. (1982b). The origin of urinary aromatic compounds excreted by ruminants 2 . The metabolism of phenolic cinnamic acids to benzoic acid. British Journal of Nutrition 47, 155-164.

Ørskov, E. R., Grub, D. A., Wenham, G. \& Corrigall, W. (1979). The sustenance of growing and fattening ruminants by intragastric infusion of volatile fatty acids and protein. British Joumal of Nutrition 41, 553-558.

Ringer, A. I. (1911). On the maximum production of hippuric acid in animals with consideration of the origin of glycocoll in the animal body. Journal of Biological Chemistry 10, 327-338.

Ross, G. J. S. (1987). Maximum Likelihood Program User Manual. Oxford: The Numerical Algorithms Group.

Scheline, R. R. (1978). Mammalian Metabolism of Plant Xenobiotics. London: Academic Press.

Schogt, J. C. M. \& Haverkamp Begemann, P. (1965). Isolation of 11-cyclohexylundecanoic acid from butter. Journal of Lipid Research 6, 466-470.

Scott, T. W., Ward, P. F. V. \& Dawson, R. M. C. (1964). The formation and metabolism of phenyl-substituted fatty acids in the ruminant. Biochemical Journal 90, 12-24.

Weekes, T. E. C. (1976). Effects of infusion of volatile fatty acids into the rumen on insulin release in sheep. Journal of Physiology 254, 80P-81P. 